\title{
Şelit Cevherinin Fiziksel ve Manyetik Alınganlık Özelliklerinden Yararlanılarak Zenginleştirilmesine Yönelik Deneysel Çalışma
}

\author{
Mahmut ALTINER *1 \\ ${ }^{1}$ Çukurova Üniversitesi, Mühendislik Mimarlık Fakültesi, Maden Mühendisliği Bölümü, Adana
}

Geliş̧ tarihi: 05.01.2017

Kabul tarihi: 31.05 .2017

\section{$\ddot{\mathbf{O} z}$}

Tungsten metali yüksek erime sıcaklığı $\left(3.410{ }^{\circ} \mathrm{C}\right)$ ve yoğunluğu $\left(19,3 \mathrm{~g} / \mathrm{cm}^{3}\right)$ nedeniyle birçok endüstriyel uygulamada kullanılmaktadır. Aydınlatma lambalarının filamenti, tungsten metalinin günlük hayatta kullanımına en güzel örnek olarak gösterilmektedir. Ancak, doğada bulunan tungsten cevherlerinin $\mathrm{WO}_{3}$ tenörü \%0,30-\%1,50 arasında değişmekte ve zenginleştirme işlemleri ile cevherin içerdiği $\mathrm{WO}_{3}$ tenörünün yükseltilmesi gereklidir. Bu sebeple Uludağ/Bursa bölgesinden alınan şelit cevherinin fiziksel ve manyetik alınganlık özelliklerinden yararlanılarak zenginleştirilmesi araştırılmıştır. Gemini masası ile cevherin $\mathrm{WO}_{3}$ tenörü \%84,37 verimle \%0,32'den \%5,01'e yükseltilmiştir. Manyetik ayırma testleri ile birlikte $\mathrm{WO}_{3}$ tenörü $\% 95$ verimle $\% 41,37$ olmuştur. Son aşamada, kavurma işleminin ardından manyetik ayırma testleri tekrarlanmış, nihai konsantrenin $\mathrm{WO}_{3}$ tenörü \% 49,94 ve zenginleştirme prosesinin verimi $\% 83,51$ olarak hesaplanmıştır.

Anahtar Kelimeler: Şelit, Gemini masası, Manyetik ayırma, Yoğunluk, Manyetik alınganlık

\section{Experimental Study on Beneficiation of Scheelite Ore through its Physical and Magnetic Susceptibility Properties}

\begin{abstract}
Tungsten metal is used in many industrial applications due to its high melting temperature $\left(3,410{ }^{\circ} \mathrm{C}\right)$ and density $\left(19.3 \mathrm{~g} / \mathrm{cm}^{3}\right)$. The filament of lamps can be shown as the best example for the daily use of tungsten metal. $\mathrm{WO}_{3}$ content of tungsten ores however varies from $0.30 \%$ to $1.50 \%$ in nature. It is necessary that the $\mathrm{WO}_{3}$ content of the ore must be increased through beneficiation methods. For this purpose, beneficiation of scheelite ore collected from Uludag/Bursa was investigated depending on its

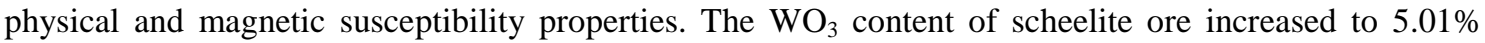
from $0.32 \%$ with $84.37 \%$ recovery using a Gemini shaking table. Thereafter, that value was upgraded to $41.37 \%$ with $95 \%$ recovery after the magnetic separation. In the last stage, roasting followed by magnetic separation tests were performed and the $\mathrm{WO}_{3}$ content of final concentrate was $49.94 \%$ and the recovery of the process conducted in this paper was calculated as $83.51 \%$.
\end{abstract}

Keywords: Scheelite, Gemini table, Magnetic separation, Density, Magnetic suspectibility

"Sorumlu yazar (Corresponding author): Mahmut ALTINER, maltiner@cu.edu.tr 


\section{GíRiș}

Tungsten, metaller arasında en yüksek erime sicaklığına sahip olması $\left(3.400{ }^{\circ} \mathrm{C}\right)$ ve yoğunluğu nedeniyle $\left(19,3 \mathrm{~g} / \mathrm{cm}^{3}\right)$, endüstriyel alanda birçok kullanım alanına (çelik, elektrik, tekstil ve deri sektörü vb.) sahiptir [1]. Endüstriyel alandaki artan bu gibi talep üzerine dünya genelinde düşük tenörlü kompleks tungsten cevherlerinin zenginleştirilmesi ile ilgili çalışmalar artmıştır [2].

Dünya genelinde tungsten cevheri tenörü $\% 0,3-1,5 \quad \mathrm{WO}_{3}$ arasında değişmekte ve zenginleştirme işlemleriyle cevherin tenörünün yükseltilmektedir. Tungsten metalini içeren cevherler volframit $\left(\mathrm{Fe}, \mathrm{Mn}\left(\mathrm{WO}_{4}\right)\right)$ ve şelit $\left(\mathrm{CaWO}_{4}\right)$ cevherleridir ve yoğunlukları sirasıyla $7,1-7,9 \mathrm{~g} / \mathrm{cm}^{3}$ ve $5,9-6,1 \mathrm{~g} / \mathrm{cm}^{3}$ arasinda değişmektedir [3].

$\mathrm{Bu}$ tip cevherlerin tenörlerinin istenilen seviyeye çıkartılması için üç ana aşama uygulanmaktadır. Bunlar; (i) tüvanan cevherin içerdiği minerallerin fiziksel özellik farklarından yararlanılarak gravite yöntemleri ile $\% 5$ ile $\% 40 \mathrm{WO}_{3}$ içeren konsantre elde edilebilir. (ii) hidrometalurjik (özütleme) ve pirometalurjik işlemler (kavurma) ile selektif şekilde $\mathrm{WO}_{3}$ konsantrasyonun yükseltilmesi sağlanabilir. (iii) hidrometalurjik işlemler ile çözeltiye alınan tungsten metali solvent ekstraksiyon, elektro-kazanım gibi yöntemler uygulanarak elde edilebilir [4].

Tungsten metalini içeren cevherlerin özgül ağırlığının yüksek olması, fiziksel yöntemler uygulanarak kolaylıkla cevherin tenörünün arttırılmasını sağlamaktadır. Ayrıca, tungsten metalini içeren cevherin özelliğine göre flotasyon ile zenginleştirme işlemi yapılabilmektedir [5-8]. Cevherin içerdiği demirli kısmın manyetik alınganlık özelliğine bağlı olarak manyetik ayırma testleri ile cevherin tenörü yükseltilebilmektedir [9].

Lu ve arkadaşları [10] yaptıkları çalışmada ön zenginleştirme aşamasında yüksek alan şiddetli yaş manyetik ayırma işleminin Falcon konsantratörüne göre daha iyi sonuçlar verdiği belirlenmiştir. Manyetik ayırma işlemiyle elde edilen konsantrenin $\mathrm{WO}_{3}$ tenörü \%7,01 (\%80,23 kazanma verimi) iken, Falcon konsantratörü kullanılarak elde edilen ürünün içerdiği $\mathrm{WO}_{3}$ miktarı $\% 0,45$ 'den \%57,25 kazanma verimiyle \%3,63'e yükselmiştir. Yapılan bir başka çalışmada ise jig, sallantılı masa ve multi gravite cihazları (MGS) kullanılarak bakırlı tungsten cevherinin zenginleştirilebilirliği araştırılmıştır [11]. Sonuçlar, sallantılı masanın diğer iki fiziksel ayırma yöntemine göre daha iyi sonuçlar verdiğini göstermiştir. Besleme malının $\mathrm{WO}_{3}$ tenörü \%1,5 iken; jig, sallantılı masa ve MGS testleri için bu değer sirasiyla \%2,85, \%8,20 ve \%4,2'e yükselmiştir. Bir başka çalışmada ise [1]; tek aşamalı jig ile $-12 \mathrm{~mm}$ tane boyutunda hazırlanan tungsten cevherinin içerdiği $\mathrm{WO}_{3}$ miktarı $\% 0,5$ 'ten $\% 4,5$ 'e yükselmiştir. Altın içeren şelit cevherinin sallantılı masa ile zenginleştirilmesi sonucunda (1 kaba -2 temizleme aşaması ile birlikte), nihai konsantre olarak elde edilen cevherin içerdiği $\mathrm{WO}_{3}$ miktarı \%0,17'den \%19,2'e yükselmiştir [12].

$\mathrm{Bu}$ çalışmada, Uludağ/Bursa bölgesinden alınan $\% 0,32 \mathrm{WO}_{3}$ tenörüne sahip şelit cevherinin fiziksel ve manyetik alınganlık özelliklerinden yararlanılarak zenginleştirilmesi araştırılmıştır. Bu çalışma, dört aşamadan oluşmuştur ve sırasıyla kırma - öğütme - eleme - sınıflandırma işlemini takiben Gemini masası ile tüvanan cevherin ön zenginleştirilmesi gerçekleştirilmiştir. Daha sonra ise cevherin içerdiği manyetik alınganlığı yüksek minerallerin uzaklaştırılması sağlanmıştır. Son aşamada ise, manyetik alınganlığı düşük minerallerin manyetik alınganlıklarının yükseltilmesi ve karbonat içerikli minerallerin içerdiği $\mathrm{CO}_{2}$ 'in ortamdan uzaklaştırılması için kavurma işlemi gerçekleştirilmiş ve son bir manyetik ayırma testi ile nihai konsantre elde edilmiştir.

\section{MATERYAL VE METOT}

\subsection{Materyal}

Deneysel çalışmalarda kullanılmak üzere yaklaşık $250 \mathrm{~kg}\left(\mathrm{~d}_{100}=100 \mathrm{~mm}\right)$ șelit cevheri Uludağ/Bursa bölgesinden alınarak Ç.Ü. Maden Mühendisliği bölüm laboratuvarlarına getirilmiştir. Çeneli kırıcı ile boyut küçültme işlemi gerçekleştirilmiş ve 
konileme-dörtleme işlemiyle cevheri temsil edecek şekilde kimyasal analiz için örnekler hazırlanmıștır. X-Ișını Floresans (XRF, PANAlytical) cihazı kullanılarak şelit cevherinin kimyasal bileşimi belirlenmiştir. Temsili olarak hazırlanan örneğin $\mathrm{WO}_{3}$ miktarı ise ICP-OES (Perkin Elmer) cihazı kullanılarak belirlenmiștir (Çizelge 1).

Çizelge 1. Uludağ/Bursa bölgesinden getirilen tüvanan cevherinin kimyasal bileşimi

\begin{tabular}{|c|c|c|c|}
\hline Element & $(\%)$ & Element & $(\%)$ \\
\hline $\mathrm{MgO}$ & 1,60 & $\mathrm{~K}_{2} \mathrm{O}$ & 0,81 \\
\hline $\mathrm{Al}_{2} \mathrm{O}_{3}$ & 4,70 & $\mathrm{CaO}$ & 35,09 \\
\hline $\mathrm{SiO}_{2}$ & 32,20 & $\mathrm{Cr}_{2} \mathrm{O}_{3}$ & 0,102 \\
\hline $\mathrm{SO}_{3}$ & 0,31 & $\mathrm{MnO}$ & 3,97 \\
\hline $\mathrm{Fe}_{2} \mathrm{O}_{3}$ & 18,41 & $\mathrm{CuO}$ & 0,075 \\
\hline $\mathrm{MoO}_{3}$ & 0,84 & $\mathrm{WO}_{3}$ & 0,32 \\
\hline \multicolumn{4}{|c|}{ Kızdırma kaybı: \%12,71 } \\
\hline
\end{tabular}

\subsection{Metot}

İlk aşamada, Uludağ/Bursa bölgesinden getirilen şelit cevheri kırma-öğütme-eleme-sınıflandırma işlemlerine tabi tutulmuş ve hedeflenen tane boyut aralığında örnekler hazırlanmıştır. Şekil 1'de gösterilen akım seması dikkate alınarak bu çalışma gerçekleştirilmiş̧ir.

Şekil 1'de temsili olarak gösterilen ve deneyler sırasında izlenen yol aşağıda ayrıntılı olarak anlatılmışır.

\section{Aşama 1}

Kırma - Öğütme - Eleme - Sınıflandırma:

$\mathrm{Bu}$ aşamada, tüvanan cevher çeneli kırıcı ve çubuklu değirmen yardımıyla yapılan ön deneylerdeki değerler dikkate alınarak $250 \mu$ m'nin altına indirilmiştir. Elek analizi işlemi sırasında $38 \mu \mathrm{m}$ 'lik eleğin altına geçen taneciklerin deneyler sırasında şlam etkisi gösterebileceği düşünülmüştür. $\mathrm{Bu}$ nedenle, zenginleştirme işlemleri öncesinde eleme ile uzaklaştırılmışıtır.

\section{Așama 2 \\ Gemini Masası ile Ön Zenginleștirme}

Deneylerde Çukurova Üniversitesi, Jeoloji Mühendisliği Bölümü’nde bulunan Gemini Masası kullanılmıştır. $-250+38 \mu \mathrm{m}$ tane boyutunda hazırlanan cevher, Gemini masası ile ön zenginleştirme işlemine tabi tutulmuş ve manyetik ayırma işlemleri öncesinde içerdiği $\mathrm{WO}_{3}$ miktarının yükselmesi hedeflenmiştir.

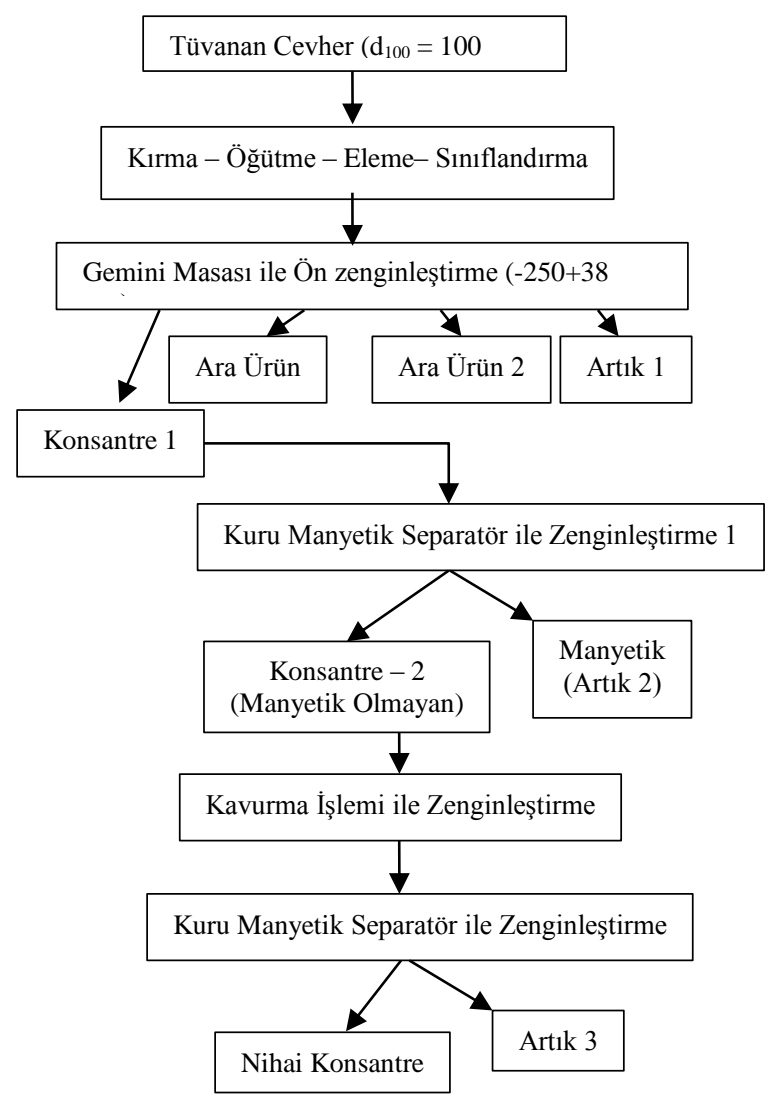

Şekil 1. Uludağ/Bursa bölgesinden alınan şelit cevherinin zenginleştirme akım şeması

Cevher masaya beslenmeden önce \%40 kat1 oranına sahip olacak şekilde su ile karıştırılmış ve sisteme palp şeklinde beslenmesi sağlanmıştır. Aynı zamanda 6 L/dk hızında yıkama suyu masa üzerine beslenmiştir. Masanın genlik uzunluğu ise 9 mm'dir ve dakikada $130 \mathrm{kez}$ vuruş hareketi gerçekleşmektedir. 
Masadan konsantre, ara ürün 1, ara ürün 2 ve artık olmak üzere 4 farklı ürün elde edilmiştir. Ürünler önceden $105{ }^{\circ} \mathrm{C}$ sicaklığa ayarlanan etüvde sabit tartıma gelinceye kadar kurutulmuştur. Her bir ürünün $\mathrm{WO}_{3}$ içeriği ICP cihazı ile belirlenmiştir. Ara ürün 1 ve Ara ürün 2 birleştirilip Gemini masasına tekrar beslenmiştir.

\section{Așama 3}

Kuru Manyetik Ayırma ile Zenginleștirme Bir önceki aşamada elde edilen konsantre, bu aşamada besleme malı olarak kullanılmıştır. Deneylerde Çukurova Üniversitesi, Jeoloji Mühendisliği Bölümü’nde bulunan Frantz Magnet marka kuru manyetik ayırma cihazı kullanılmıştır. Deneylerde cihazın eğimi $20^{\circ}$ olacak şekilde sabit tutulmuştur. 5 farklı Gauss (2.000, 4.000, 8.000, 12.000 ve 15.000 ) şiddetinde deneyler gerçekleştirilmiştir. Her bir ürünün $\mathrm{WO}_{3}$ içeriği ICP cihazı ile belirlenmiştir.

\section{Așama 4}

\section{Kavurma ve Kuru Manyetik Ayırma İșlemi}

$\mathrm{Bu}$ aşamada, bir önceki aşamada elde edilen konsantre $800{ }^{\circ} \mathrm{C}$ sicaklıkta 1 saat boyunca kül firınında kavurma işlemine tabi tutulmuştur. Belirtilen süre sonunda, numunenin ağırlık kaybı ölçülmüş ve kavurma işlemi sonunda elde edilen ürünün $\mathrm{WO}_{3}$ içeriği daha önce belirtilmiş olan yöntemler kullanılarak belirlenmiştir. Ayrıca numune tekrar kuru manyetik ayırma cihazı ile zenginleştirme işlemine tabi tutulmuş ve kavurma işlemi ile manyetik özelliği arttırıldığı düşünülen demirli kısım ile şelit cevherinin ayrılması hedeflenmiştir.

Tüm işlemler sonucunda, Rigaku Miniflex II XIşını difraksiyon (XRD) cihazı kullanılarak elde edilen nihai ürünün mineral kompozisyonu belirlenmiştir. Her bir aşamada zenginleştirme verimi aşağıda verilen Eşitlik 1 kullanılarak hesaplanmıştır.

$\mathrm{V}=\frac{\mathrm{C}_{1} \times \mathrm{c}_{2}}{\mathrm{~F}_{1} \times \mathrm{f}_{2}} \times 100$

$\mathrm{V}=$ Zenginleştirme verimi $(\%)$
$\mathrm{C}_{1}=$ Konsantre miktarı $(\%)$

$\mathrm{c}_{2}=$ Konsantrenin içerdiği $\mathrm{WO}_{3}$ tenörü $(\%)$

$\mathrm{F}_{1}=$ Besleme malı miktarı $(\%)$

$\mathrm{f}_{2}=$ Besleme malının içerdiği $\mathrm{WO}_{3}$ tenörü (\%) değerlerini göstermektedir.

\section{ARAŞTIRMA BULGULARI}

\subsection{Gemini Masası ile Ön Zenginleştirme}

Yoğunluk fark1 prensibine göre çalışan zenginleştirme cihazlarında, iki tanecik arasındaki yoğunluk farkı 2'den fazla ise ayrım oldukça kolay olmaktadır [13]. Şelit cevherinin özgül ağırlığı 5,9 ile $6,1 \mathrm{~g} / \mathrm{cm}^{3}$ arasinda iken, gang mineral olarak adlandırılan diğer minerallerin yoğunlukları 2,6 ile $4,3 \mathrm{~g} / \mathrm{cm}^{3}$ arasında değișmektedir. Manyetit cevherinin ise yoğunluğu $5-5,5 \mathrm{~g} / \mathrm{cm}^{3}$ arasinda olup şelit cevherinin yoğunluğuna oldukça yakındır. Bu bilgiler 1şı̆̆ında, Gemini masası ile yapılan zenginleştirme işleminde şelit cevherinin bünyesindeki kalsit ve kuvars gibi gang minerallerin uzaklaştırılabileceği ön görülmüştür.

Zenginleştirme işlemleri sırasında şlam etkisinin önlenebilmesi ve $\mathrm{CaWO}_{4}$ 'ün şlam içinde kaçak olmaması için kontrollü bir şekilde çubuklu değirmen ile öğütme işlemi gerçekleştirilmiştir. Öğütme işlemi sırasında $10 \mathrm{dk}$ 'da bir değirmen durdurulmuş ve elek analizi yapılarak $-250+38 \mu \mathrm{m}$ boyutuna indirilen malzeme ayrılmış ve aynı miktarda yeni besleme malı eklenmiş ve öğütme işlemine devam edilmiştir. Tüvanan cevherin $d_{100}$ değeri kırma-öğütme-eleme-sınıflandırma işlemleri ile birlikte $250 \mu \mathrm{m}$ 'nin altına indirilmiştir. Her bir deneyde kullanılan besleme malı miktarı 10 kg'dır.

Şekil 2'de görüldüğü gibi, masa üzerine beslenen cevherden dört farklı ürün elde edilmiştir. Yoğunluk farkına prensibine bağlı olarak yapılan ayrım sonucunda 1 numaralı hazne kısmından yoğunluğu düşük olan ürünler artık olarak alınmıştır. 2 ve 3 numaralı haznelerden ise "ara ürün" olarak adlandırılan örnekler elde edilmiştir. Yoğunluğu fazla olan ve konsantre olarak 
adlandırılan tanecikler ise 4 numaralı hazneden masayı terk etmiştir.

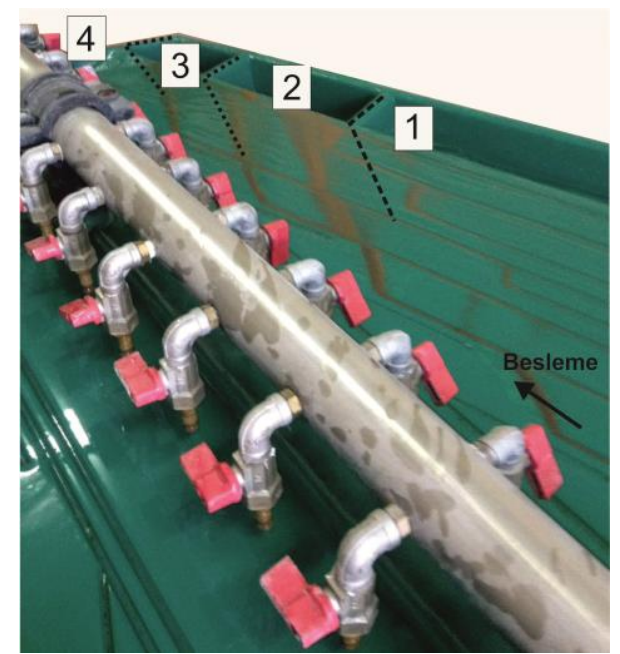

Şekil 2. Zenginleştirme işleminde kullanılan Gemini masasına ait görüntü (1: artık, 2: ara ürün, 3: ara ürün 2, 4: konsantre)

Deney sonunda elde edilen dört farklı ürünün ağırlıkları \%5,39 konsantre, \%2,34 ara ürün 1 , $\% 5,54$ ara ürün 2 ve $\% 86,74$ artık olarak belirlenmiştir. Gemini masasının zenginleştirme veriminin hesaplanabilmesi için XRF cihazı yardımıyla gerçekleştirilen deneylerde konsantre, ara ürün 1, ara ürün 2 ve artık olarak adlandırılan numunelerin içerdiği $\mathrm{Fe}_{2} \mathrm{O}_{3}, \mathrm{CaO}, \mathrm{Al}_{2} \mathrm{O}_{3}, \mathrm{SiO}_{2}$, $\mathrm{SO}_{3}, \mathrm{MnO}, \mathrm{MoO}_{3}$ ve $\mathrm{WO}_{3}$ miktarları belirlenmiştir (Çizelge 2).

Görüldüğü gibi, besleme malının içeriği $\mathrm{WO}_{3}$ miktarı \%0,32 iken, Gemini masası ile yapılan ön zenginleştirme işlemiyle birlikte bu değer \%5,01'e yükselmiştir. Zenginleştirme verimi \%84,37 olarak belirlenmiştir. Literatürde yapılan çalışmalar ile kıyaslandığında [1]; jig ile yapılan ön zenginleştirmeye göre Gemini masasının daha yüksek verimde çalıştığ 1 belirlenmiştir. $\mathrm{Bu}$ farklılı̆̆ın cevherin tane boyutu serbestleşmesi ile alakalı olduğu düşünülmektedir. Daha iri boyutlarda çalışan jig cihazında yapılabilecek bir ön zenginleştirme işlemi nedeniyle yüksek $\mathrm{WO}_{3}$ içeriğine sahip artık elde edilmesine neden olacağı tahmin edilmiştir.
Çizelge 2. Gemini masası deneylerinde elde edilen dört farklı ürünün kimyasal bileşimleri

\begin{tabular}{|c|c|c|c|c|}
\hline \multicolumn{5}{|c|}{ Konsantre } \\
\hline \multirow{5}{*}{$\begin{array}{c}\text { Ağ1rl1k } \\
\% 5,39\end{array}$} & Element & $(\%)$ & Element & $(\%)$ \\
\hline & $\mathrm{Al}_{2} \mathrm{O}_{3}$ & 3,00 & $\mathrm{CaO}$ & 18,70 \\
\hline & $\mathrm{SiO}_{2}$ & 16,40 & $\mathrm{MnO}$ & 4,12 \\
\hline & $\mathrm{SO}_{3}$ & 6,20 & $\mathrm{MoO}_{3}$ & 2,70 \\
\hline & $\mathrm{Fe}_{2} \mathrm{O}_{3}$ & 42,58 & $\mathrm{WO}_{3}$ & 5,01 \\
\hline \multicolumn{5}{|c|}{ Ara Ürün - 1} \\
\hline \multirow{5}{*}{$\begin{array}{c}\text { Ağırlık } \\
\% 2,34\end{array}$} & Element & $(\%)$ & Element & $(\%)$ \\
\hline & $\mathrm{Al}_{2} \mathrm{O}_{3}$ & 3,60 & $\mathrm{CaO}$ & 22 \\
\hline & $\mathrm{SiO}_{2}$ & 18,30 & $\mathrm{MnO}$ & 4,89 \\
\hline & $\mathrm{SO}_{3}$ & 5,40 & $\mathrm{MoO}_{3}$ & 1,80 \\
\hline & $\mathrm{Fe}_{2} \mathrm{O}_{3}$ & 41,01 & $\mathrm{WO}_{3}$ & 1,08 \\
\hline \multicolumn{5}{|c|}{ Ara Ürün - 2} \\
\hline \multirow{5}{*}{$\begin{array}{c}\text { Ağırlık } \\
\% 5,54\end{array}$} & Element & $(\%)$ & Element & $(\%)$ \\
\hline & $\mathrm{Al}_{2} \mathrm{O}_{3}$ & 4,40 & $\mathrm{CaO}$ & 26,2 \\
\hline & $\mathrm{SiO}_{2}$ & 20,30 & $\mathrm{MnO}$ & 5,44 \\
\hline & $\mathrm{SO}_{3}$ & 4,22 & $\mathrm{MoO}_{3}$ & 0 \\
\hline & $\mathrm{Fe}_{2} \mathrm{O}_{3}$ & 34,36 & $\mathrm{WO}_{3}$ & 0,46 \\
\hline \multicolumn{5}{|c|}{ Artık } \\
\hline \multirow{5}{*}{$\begin{array}{l}\text { Ağırlık } \\
\% 86,74\end{array}$} & Element & $(\%)$ & Element & $(\%)$ \\
\hline & $\mathrm{Al}_{2} \mathrm{O}_{3}$ & 5,41 & $\mathrm{CaO}$ & 40,17 \\
\hline & $\mathrm{SiO}_{2}$ & 36,72 & $\mathrm{MnO}$ & 4,62 \\
\hline & $\mathrm{SO}_{3}$ & 0,32 & $\mathrm{MoO}_{3}$ & 0,85 \\
\hline & $\mathrm{Fe}_{2} \mathrm{O}_{3}$ & 21,13 & $\mathrm{WO}_{3}$ & 0,20 \\
\hline
\end{tabular}

Çizelge 2'de verilen kimyasal analiz sonuçları incelendiğinde; ürünün içerdiği $\mathrm{WO}_{3}$ miktarındaki artışa paralel olarak $\mathrm{Fe}_{2} \mathrm{O}_{3}$ oranı yükselmiş, $\mathrm{SiO}_{2}$ ve $\mathrm{CaO}$ oranları düşmüştür. $\mathrm{Bu}$ durum, yoğunluk fark1 prensibine göre çalışan zenginleştirme sisteminde beklenen bir durumdur. Bu aşamada elde edilen nihai konsantre, Şekil 1'de verilen akım şemasından da anlaşılacağı üzere manyetik ayırma deneylerinde besleme malı olarak kullanılmıştır.

\subsection{Kuru Manyetik Ayırma ile Zenginleștirme}

$\mathrm{Bu}$ aşamada, dört farklı Gauss şiddetinde kuru manyetik ayırma deneyleri gerçekleştirilmiştir. Çizelge 3'de dört farklı Gauss şiddetinde gerçekleştirilen deneyler sonucunda elde edilen manyetik ve manyetik olmayan ürünlerin yüzdece ağırlıkları ve $\mathrm{WO}_{3}$ içerikleri verilmiştir.

Elde edilen değerlerin daha iyi anlaşılabilmesi için Çizelge 3'de verilen değerler kullanılarak Şekil 3'de görülen grafik çizilmiştir. Eğer 2.000 
Gauss şiddetinde manyetik ayırma işlemleri gerçekleştirilirse elde edilen manyetik olmayan ürünün $\mathrm{WO}_{3}$ değeri \%15'in altında olmuştur.

Çizelge 3. Farklı Gauss şiddetlerinde yapılan manyetik ayırma testlerinden elde edilen manyetik olmayan ürünlerin yüzdece ağırlıkları ve $\mathrm{WO}_{3}$ içerikleri

\begin{tabular}{|c|c|c|c|c|}
\hline \multirow{2}{*}{$\begin{array}{c}\text { Gauss } \\
\text { Şiddeti }\end{array}$} & \multicolumn{2}{|c|}{$\begin{array}{c}\text { Manyetik } \\
\text { Olmayan Ürün }\end{array}$} & \multicolumn{2}{c|}{ Manyetik Ürün } \\
\cline { 2 - 5 } & $\begin{array}{c}\text { A ğırlık } \\
(\%)\end{array}$ & $\begin{array}{c}\mathrm{WO}_{3} \\
(\%)\end{array}$ & $\begin{array}{c}\text { Ağırlık } \\
(\%)\end{array}$ & $\begin{array}{c}\mathrm{WO}_{3} \\
(\%)\end{array}$ \\
\hline 2.000 & 25,01 & 10,66 & 74,99 & 0,80 \\
\hline 4.000 & 12,85 & 37,17 & 87,15 & 0,27 \\
\hline 8.000 & 11,63 & 41,57 & 88,37 & 0,20 \\
\hline 12.000 & 11,70 & 42,08 & 88,30 & 0,10 \\
\hline 15.000 & 10,92 & 43,44 & 89,08 & 0,30 \\
\hline
\end{tabular}

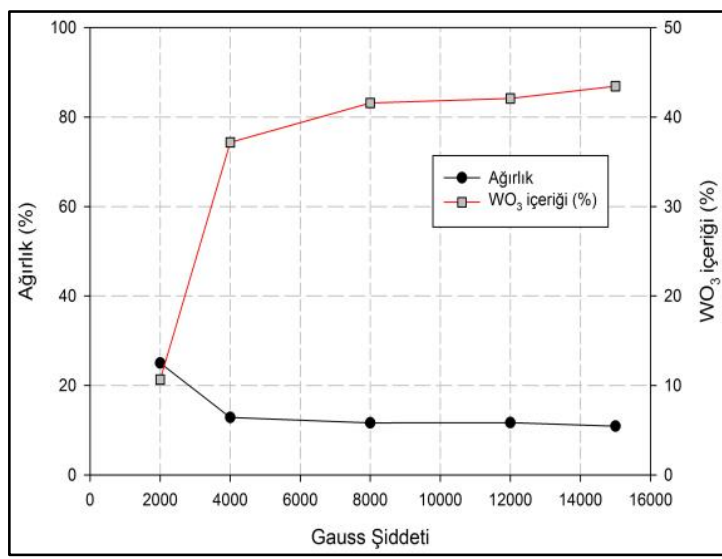

Şekil 3. Manyetik ayırma şiddetine bağlı olarak elde edilen manyetik olmayan numune miktarı ve $\mathrm{WO}_{3}$ değerleri

Uygulanan 8.000 Gauss şiddetinde elde edilen ürün miktarı ağırlıkça $\% 11,63$ ve içerdiği $\mathrm{WO}_{3}$ miktarı \%41,57 olarak belirlenmiştir. Daha yüksek Gauss şiddetlerinde gerçekleştirilen manyetik ayırma deneylerinde elde edilen ürünlerin $\mathrm{WO}_{3}$ değerleri birbirine oldukça yakın çıkmıştır.

Gauss şiddeti ve zenginleştirme verimleri arasındaki ilişki Şekil 4'de verilmiştir. Gauss şiddeti 2.000 iken, zenginleştirme verimi \%50'in altında kalmıştır. Gauss şiddeti 2.000'den 4.000'e yükseldiğinde ise zenginleştirme verim değeri \%90'ın üzerine çıkmıştır.
Sonuç olarak; gerçekleştirilen manyetik ayırma deneylerinde zenginleştirme verimleri dikkate alındığında en iyi Gauss şiddeti 8.000 olarak belirlenmiştir. Elde edilen nihai ürünün kimyasal içeriği Çizelge 4'de görülmektedir.

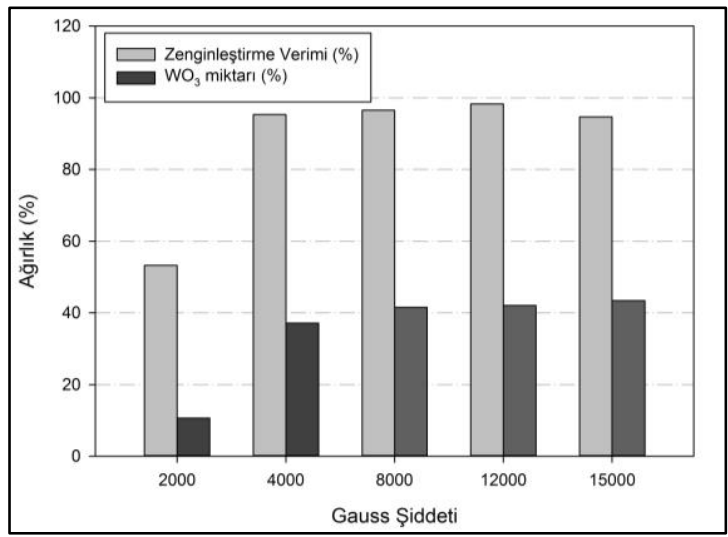

Şekil 4. Gauss şiddetine bağlı olarak şelit cevherinin zenginleştirme verimi

Çizelge 4. Manyetik ayırma işlemler sonucunda en iyi zenginleştirme verimine sahip ürünün içeriği

\begin{tabular}{|c|c|c|c|}
\hline Element & $\begin{array}{c}\text { Miktar } \\
(\%)\end{array}$ & Element & $\begin{array}{c}\text { Miktar } \\
(\%)\end{array}$ \\
\hline $\mathrm{Bi}_{2} \mathrm{O}_{3}$ & 2,72 & $\mathrm{CaO}$ & 19,18 \\
\hline $\mathrm{SiO}_{2}$ & 16,27 & $\mathrm{MnO}$ & 0,498 \\
\hline $\mathrm{SO}_{3}$ & 6,30 & $\mathrm{MoO}_{3}$ & 7,70 \\
\hline $\mathrm{Fe}_{2} \mathrm{O}_{3}$ & 5,86 & $\mathrm{WO}_{3}$ & 41,57 \\
\hline
\end{tabular}

\subsection{Kavurma ve Kuru Manyetik Ayırma ile Zenginleştirme}

Bir önceki aşamada 8.000 Gauss şiddetinde yapılan manyetik ayırma işlemi sonucunda elde edilen ve $\mathrm{WO}_{3}$ miktarı \%41,57 olan nihai ürün, $800{ }^{\circ} \mathrm{C}$ sicaklıkta 1 saat boyunca kavurma işlemine tabi tutulmuştur. Belirtilen süre sonunda ürünün $\mathrm{WO}_{3}$ miktarı \%41,57'den \%47,24'e yükselmiştir (Çizelge 5).

Ayrıca, kavurma işlemi ile birlikte nihai ürünün içerdiği demirli kısmın manyetik alınganlık özelliği arttırılması hedeflenmiştir. Bu sebeple, ürün bir önceki aşamada uygun değer olarak belirlenen Gauss şiddetinde manyetik ayırma 
testine tabi tutulmuştur. Elde edilen sonuçlar (Çizelge 4 ve 6) kavurma sonrası demirli kısmın manyetik alınganlık özelliğinin arttığını göstermektedir. Elde edilen bu bulgu literatürde yapılmış olan önceki çalışmaları destekler niteliktedir [14-16]. Nihai ürün olarak adlandırılan ürünün $\mathrm{WO}_{3}$ içeriği böylece \%49,94'e yükselmiştir (Çizelge 6).

Çizelge 5. Kavurma işlemi sonunda elde edilen ürünün içeriği

\begin{tabular}{|c|c|c|c|}
\hline Element & $(\%)$ & Element & $(\%)$ \\
\hline $\mathrm{Bi}_{2} \mathrm{O}_{3}$ & 3,09 & $\mathrm{CaO}$ & 21,80 \\
\hline $\mathrm{SiO}_{2}$ & 19,49 & $\mathrm{MnO}$ & 0,57 \\
\hline $\mathrm{SO}_{3}$ & 6,16 & $\mathrm{MoO}_{3}$ & 8,75 \\
\hline $\mathrm{Fe}_{2} \mathrm{O}_{3}$ & 6,66 & $\mathrm{WO}_{3}$ & 47,24 \\
\hline
\end{tabular}

Çizelge 6. İkinci manyetik ayırma işlemi sonucunda elde edilen nihai ürünün içeriğ $i$

\begin{tabular}{|c|c|c|c|}
\hline Element & $(\%)$ & Element & $(\%)$ \\
\hline $\mathrm{Bi}_{2} \mathrm{O}_{3}$ & 3,27 & $\mathrm{CaO}$ & 23,04 \\
\hline $\mathrm{SiO}_{2}$ & 20,55 & $\mathrm{MnO}$ & 0,60 \\
\hline $\mathrm{SO}_{3}$ & 6,57 & $\mathrm{MoO}_{3}$ & 9,25 \\
\hline $\mathrm{Fe}_{2} \mathrm{O}_{3}$ & 0,60 & $\mathrm{WO}_{3}$ & 49,94 \\
\hline
\end{tabular}

Nihai konsantreye ait XRD grafiği Şekil 5'de verilmiştir. Görüldüğü gibi; şelit cevherinin yanı sıra, kuvars, hematit, molibdenit ve bizmut mineralleri tespit edilmiştir. Elde edilen nihai şelit konsantresi, hidrometalurjik yöntemlerle tungsten metalinin üretimi için uygun değerdedir [17-19].

\section{SONUÇLAR}

Bu çalışmada, Uludağ/Bursa bölgesinden getirilen şelit cevherinin fiziksel ve manyetik özellik farklılıklarından yararlanılarak zenginleştirilmesi araştırılmıştır. Tüvanan cevherin $\mathrm{WO}_{3}$ içeriği \%0,32 iken, dört farklı aşamada zenginleştirme işlemine tabi tutulan cevherin $\mathrm{WO}_{3}$ içeriği \%49,94'e yükseltilmiştir. Önerilen akım şemasında, sisteme 1 ton tüvanan cevher beslenirse $5,35 \mathrm{~kg}$ konsantre ürün elde edilecek ve şelit cevherinin genel zenginleştirme verimi \%83,51 olacaktır. Ancak, XRD grafiğinden de anlaşılacağ 1 gibi; nihai konsantrenin içinde istenmeyen kuvars ve hematit gibi mineraller tespit edilmiştir.
Yoğunluk farkı ve manyetik alınganlık özelliklerine göre bu minerallerin ayrılması beklenmekteydi. Bu problemin tane boyut dağılımı ile alakalı olduğu düşünülmektedir. Daha ince boyutlarda yapılabilecek çalışmada bu gang minerallerinde uzaklaştırılmasının sağlanacağı düşünülmektedir. Buna karşın, boyut küçültme işlemine bağlı olarak Gemini masasının çalışma verimi düşebilecektir. $\mathrm{Bu}$ sebeple, daha ince boyutlarda flotasyon işlemi gerçekleştirilebilir ve daha yüksek verimlerde zenginleştirme sağlanabilecektir. Şelit konsantresi amonyum paratungstat (APT) üretimi için hammadde olarak kullanılmaktadır. Literatürde $\% 5$ ile $\% 20 \quad \mathrm{WO}_{3}$ tenörlü cevherlerin APT üretiminde kullanılabildiği belirtilmiştir [20]. Bu sebeple, bu çalışmada üretilen şelit konsantresi, seçimli özütleme işlemine tabi tutulacak ve ilerleyen zamanlarda APT üretimi için yapılacak çalışmada hammadde olarak kullanılacaktır. Ayrıca, nihai artık olarak elde edilen ürünün $\mathrm{Fe}_{2} \mathrm{O}_{3}$ değeri oldukça yüksek $(\% 59,17)$ ve ekonomik olarak değerlendirilebilecek niteliktedir.

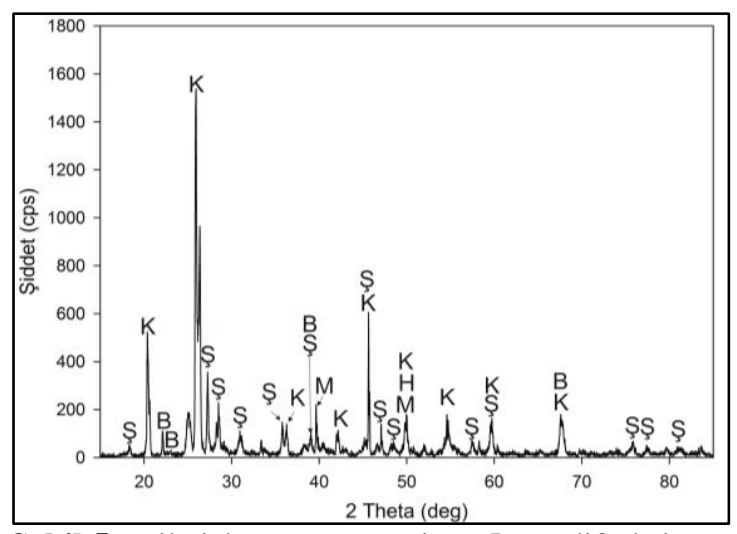

Şekil 5. Nihai konsantreye ait X-Işını difraksiyon (XRD) grafiği (Ş: Şelit, K: Kuvars, B: Bizmut, M: Molibdenit, H: Hematit)

\section{TEŞEKKÜR}

Yazar, bu çalışmada laboratuvar imkanlarının kullanılmasına izin veren Öğr. Gör. Dr. Fatih KARAOĞLAN'a, deneyler sırasında yardımları için Arş. Gör. Emrah ŞİMŞEK'e ve katkıları için Prof. Dr. Mehmet YILDIRIM'a teşekkürü bir borç bilir. 


\section{KAYNAKLAR}

1. Srivastava, J.P., Pathak, P.N., 2000. Preconcentration: A Necessary Step for Upgrading Tungsten ore, Int. J. Miner. Process., vol. 60, pp. $1-8$.

2. Dongfang, L., Yuhua, W., Tao, J., Wei S., HU, Y., 2016. Study on Pre-concentration Efficiency of Wolframite from Tungsten ore Using Gravity and Magnetic Separations, Physicochem. Probl. Miner. Process., vol. 52, p. 719-729.

3. Blackburn, W. H., Denner, W. H., 1988. Principles of Mineralogy, 413 pp. $1^{\text {st }}$ edition, W.C. Browns Publishers, Dubuque, Iowa, USA.

4. Srinivas, K., Sreenivas, T., Natarajan, R.,. Padmanabhan N.P.H., 2000. Studies on the Recovery of Tungsten from a Composite Wolframite-scheelite Hydrometallurgy, vol. 58, pp. 43-50.

5. Gao, Y., Gao, Z., Sun, W., Hu, Y., 2016. Selective Flotation of Scheelite from Calcite: A Novel Reagent Scheme. International Journal of Mineral Processing, vol. 154, pp. 10-15.

6. Feng, B., Guo, W., Xu, H., Peng, J., Luo, X., Zhu, X., 2017. The Combined Effect of lead Ion and Sodium Silicate in the Flotation Separation of Scheelite from Calcite. Separation Science and Technology, vol. 52(3), pp. 567-573.

7. Bhatti, M.A., Kazmi K. R., Mehmood, R., akram, A., 2014. Flotation Study on Scheelite ore of Chitral, Khyber Pakhtoonkhwa, Pakistan. Pakistan Journal of Scientific and Industrial Research. Series A. Physical Sciences, vol. 145 (3), pp. 145-153.

8. Hui, S., 2015. Flotation Experiments of a Lowgrade Scheelite. Metal Mine, 1, 015.

9. Weiss, N. L., 1985. SME Mineral Processing Hand book, vol. 2, Section 27, 18 pp, Society of Mining Engineers (SME) of AIME, New York, USA.

10. Lu, D., Wang, Y., Jiang, T., Sun, W., Hu, Y., 2016. Study on Pre-concentration Efficiency of Wolframite from Tungsten ore using Gravity and Magnetic Separations. Physicochemical Problems of Mineral Processing, vol. 52(2), pp. 718-728.
11. Hedayati H. S., Noaparast, M., Tonkaboni, S. Z. S. M., Hosseini, S. M., 2016. Application of Gravity Separators for Enrichment of South Chah-Palang Tungsten Ore. Int. Journal of Mining \& Geo-Engineering, vol. 50(1), pp. 1-12.

12. Greaves, J. N., 1989. Tungsten and Gold Recovery from Alaskan Scheelite-bearing Ores. Report of Investigations 9251, Bureau of Mines and United States Department of the Interior.

13. Wills, B. A., 1992. Mineral Processing Technology, 464 pp. $5^{\text {th }}$ Edition, Pergamon Press, New York, USA.

14. Cui, Z., Liu, Q., Etsell, T. H. 2002. Magnetic Properties of Ilmenite, Hematite and Oilsand Minerals After Roasting. Minerals Engineering, vol. 15(12), pp. 1121-1129.

15. Hrouda, F., 2003. Indices for Numerical Characterization of the Alteration Processes of Magnetic Minerals Taking Place During Investigation of Temperature Variation of Magnetic Susceptibility. Studia Geophysica et Geodaetica, vol. 47(4), pp. 847-861.

16. Merritt, R. R., Cranswick, L. M. D., 1994. The Origin of Magnetic Susceptibility in Roasted Ilmenite. In $6^{\text {th }}$ AusIMM Extractive Metallurgy Conference. Melbourne: The Australian Institute of Mining and Metallurgy (pp. 171-180).

18. Kazmi, K. R., Bhatti, M.A., Bhatti, A., Mehmood, A., Anwar, M.S., Sheikh, S.T., 2012. Beneficiation Studies on Low-grade Tungsten Ore of Chitral, Khyber Pukhtunkhwa, Pakistan, Pakistan Journal of Scientific and Industrial Research, vol. 55, pp.8-13.

18. Guar, R.P. S., $2006 . \quad$ Modern Hydrometallurgical Production Methods for Tungsten, Journal of the Minerals, Metals and Materials Society, vol 58, pp. $45-49$.

19. Razavizadeh, H., Langroudi, A.E., 2006. Production of Tungsten Via Leaching of Scheelite With Sulfuric Acid, Minerals and Metallurgical Processing, vol. 23, pp.67-72.

20.Zhao, Z., Li H., Liu, M., Sun, P., Li Y., 1996. Soda Decomposition of Low-grade Tungsten ore Through Mechanical Activation, Journal of Central South University of Technology, vol. 3 pp. 181-184. 